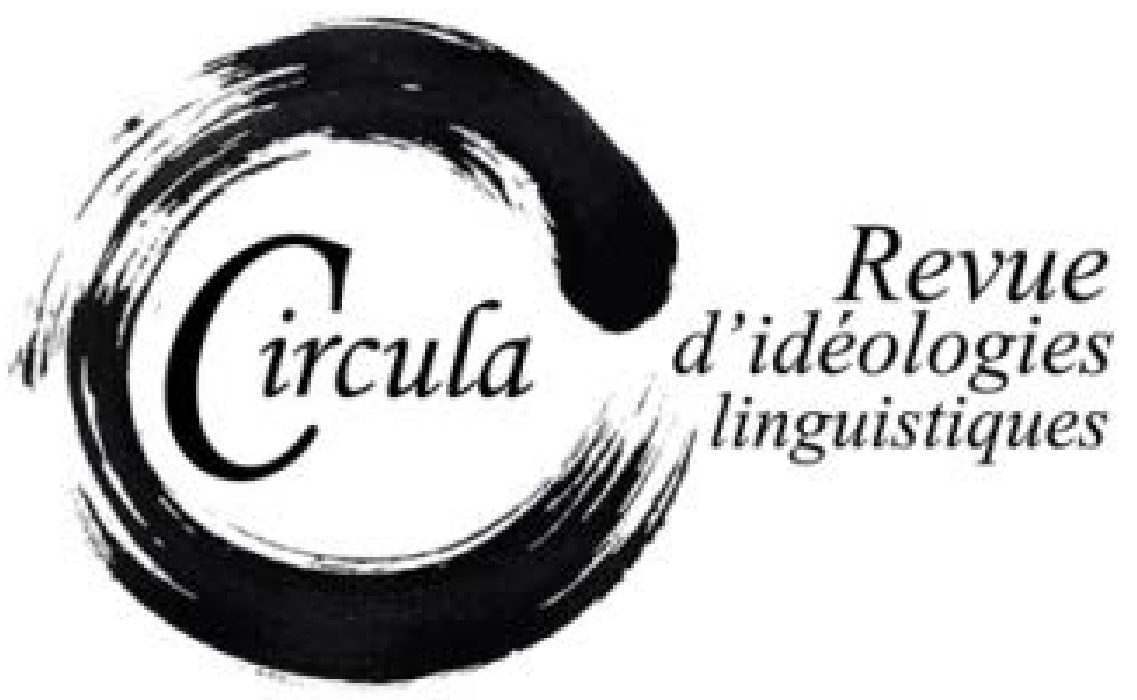

Titre: Álex Grijelmo, “Cronista” del lenguaje de El País

Auteur(s): Franz LebSANFT, RhEINISCHE FrIEDRICH-WILHELMS-UNIVERSITÄT BONN

Revue: Circula, numéro 6

PAgES: $1-17$

ISSN: 2369-6761

DiRecteurs: Wim Remysen, Sabine SchWARze et JuAn Antonio EnNis

URI: HTTP://HDL.HANDLE.NET/11143/11928

DOI: HTTPS://DOI.ORG/10.17118/11143/11928 


\section{Álex Grijelmo, "cronista" del lenguaje de El País}

Franz Lebsanft, Rheinische Friedrich-Wilhelms-Universität Bonn

franz.lebsanft@uni-bonn.de

Resumen: El periodista Álex Grijelmo es el más destacado “cronista” (columnista) del lenguaje en la España actual. Con sus artículos se inscribe en una tradición textual representada, entre otros, por el lingüista Fernando Lázaro Carreter. El análisis cualitativo de un corpus de 121 columnas permite describir un ideal normativo basado en el concepto retórico de la puritas. Situando el problema de la ejemplaridad lingüística en una dialéctica bastante sofisticada entre los niveles de la lengua y el discurso, Grijelmo defiende una norma prescriptiva mucho más elitista que la de las Academias de la lengua española.

Palabras clave: Álex Grijelmo; crónica (columna) lingüística; norma lingüística; purismo

Abstract: The journalist Álex Grijelmo is the most outstanding language columnist in present-day Spain. His articles form part of a textual tradition represented, among others, by the linguist Fernando Lázaro Carreter. The qualitative analysis of a corpus of 121 columns allows for describing a normative ideal based on the rhetorical concept of puritas. Placing the problem of linguistic exemplarity in a rather sophisticated dialectic reasoning between the levels of language and discourse, Grijelmo defends a prescriptive norm even more elitist than that of the Academies of the Spanish language.

Keywords: Álex Grijelmo; language column; linguistic norm, purism 
"Finally, a confession. When I hear someone use disinterested to mean 'apathetic', I am apt to go into rage."

(Pinker, [1994]/2011: 416)

\section{Introducción: Una tradición textual y su denominación}

En el momento de formular el título de este artículo pensaba - y, para decir la verdad, sigo pensando - que el nombre de Álex Grijelmo, autor de tantos best sellers sobre la norma lingüística', causaría quizás menos sorpresa que la aposición "cronista del lenguaje de El País". La explicación de "cronista" da por entendido que el género periodístico al que pertenece la columna semanal La punta de la lengua, publicada en El País desde el 4 de agosto de 2013², es un tipo de crónica, es decir - según el "manual" del Libro de estilo de este periódico madrileño -, "un texto de estilo interpretativo basado en una noticia, y [que] parte de un hecho inmediato” (El País, 2014: 58). Efectivamente, esta breve caracterización se puede aplicar a muchos de los textos de Grijelmo³. Así, el 13 de julio de 2014 el artículo que se intitula "Abdicar la corona con corrección" hace referencia a la abdicación de Juan Carlos I en junio del mismo año, cuando el Rey había firmado la correspondiente ley en la que se declara que "Su Majestad el Rey Don Juan Carlos I de Borbón abdica la Corona de España" (Boletín Oficial del Estado, jueves, 19 de junio de 2014, Sec. I: 46398). Apoyándose en los diccionarios académicos, Grijelmo (13 de julio de 2014) analiza el empleo raro, transitivo del verbo "en su sentido constitucional"4 y concluye sus reflexiones sobre este régimen verbal con la frase "interpretativa" de que el soberano "abdicó la Corona, pero no del uso correcto del español". Este análisis sugiere la idea de que los contenidos de las puntas pueden figurar bajo el lema general "interpretación más información” donde caben, entre otros, los géneros “crónica” y "análisis” (El País, 2014: 45). Sin embargo, el periódico publica los textos de Grijelmo siempre en la sección de "opinión”, sección reservada a otros géneros periodísticos diferentes. De ahí que quizás sea más apropiado clasificar las puntas

1. V. Grijelmo (1998, 2000, 2004a, 2006). Sobre la importancia de la opinión normativa de Álex Grijelmo en el ámbito español e hispánico v. Lebsanft (1997: 241-245) y, veinte años después de esta primera valoración, Lebsanft (2017).

2. En el momento de entregar este artículo para su publicación, la última columna publicada, "'Dress code' sale de fiesta”, lleva la fecha de 1 de enero de 2017.

3. Para una caracterización más extensa, v. Grijelmo (1997: 82): "La crónica toma elementos de la noticia, del reportaje y del análisis. Se distingue de los dos últimos en que prima el elemento noticioso y en muchos periódicos suele titularse efectivamente como una noticia (salvo las crónicas taurinas y deportivas, en que se emplean por lo general tipografías diferentes). Y se distingue de la noticia porque incluye una visión personal del autor." V. también Martínez Albertos (52007: 346): "Lo más parecido a las crónicas latinas - de Francia, Italia o España - serían los artículos de los columnistas norteamericanos o británicos. Pero las "columnas" son géneros periodísticos fundamentalmente para el comentario, en tanto que la crónica latina arrastra consigo todavía cierta dosis de carga informativa, de actividad característica de un reportero y no de un editorialista."

4. DLE ${ }^{23} 2014$, s.v. "abdicar": "Dicho de un monarca: Ceder la soberanía de su reino o su corona a otro, o renunciar a ella". V. también DEA, s.V. "abdicar": "A tr 1 Traspasar [un soberano (suj) su reino, el trono o la corona (cd) a otra pers. (compl EN)]". 
como "columnas" o "tribunas", y denominar al autor de estos textos como columnista de (l) lenguaje. Aun así, ni la denominación columnista de(l) lenguaje ni cronista de(I) lenguaje son expresiones muy usuales en español, a diferencia del inglés y del francés donde las expresiones análogas language columnist y chroniqueur de langage, respectivamente, están muy bien arraigadas en la tradición periodística hasta el punto de que desde hace mucho tiempo los lingüistas estiman necesario, al menos en el caso del francés, ocuparse del objeto que representa ${ }^{6}$. Sin embargo, la ausencia de una expresión usual para designar a los cronistas o columnistas del lenguaje no impide ni mucho menos que exista una tradición de ese oficio en el periodismo español e hispanoamericano. Álex Grijelmo (10 de abril de 2013) es el primero en referirse a esa tradición cuando publica un reportaje sobre la divulgación lingüística bajo el titular "El dardo en lo ostentóreo". Mientras que esta última palabra, ostentóreo, evoca el famoso término involuntariamente acuñado por el político y empresario Jesús Gil, resultado de un cruce entre ostentoso y estentóreo, aquella primera palabra dardo inscribe el libro del lexicógrafo y académico José Antonio Pascual No es lo mismo ostentoso que ostentóreo (Pascual, 2013) en la tradición del célebre Dardo en la palabra de Fernando Lázaro Carreter (Lázaro Carreter, 1997) ${ }^{7}$. Por cierto, el mismo Grijelmo habría elegido la palabra punta en homenaje al ilustre filólogo.

\section{Corpus}

Antes de publicar los dardos en forma de libro, Lázaro Carreter los había publicado en el diario madrileño Informaciones y en otros periódicos (Lázaro Carreter, 1997: 19). Evidentemente, el formato "libro" da mucho más peso a la volatilidad de la prosa periodística y, por eso, no sorprende que Grijelmo, autor de muchos libros, le siga y, de igual modo, recoja sus puntas entre las cubiertas de un libro. Palabras de doble filo. Avisos y antídotos contra engaños y calamidades reúne los textos lingüísticos publicados en el diario madrileño El País desde el 25 de abril de 2012 hasta febrero de 2015 (Grijelmo, 2015). El corpus en el que este artículo se basa consiste en esas tribunas y columnas y las que se han publicado después, hasta finales de setiembre de $2015^{8}$. En total, son 121 artículos, de los que 84 constan en el libro mencionado. Palabras de doble filo no es el primer libro en el que

5. Columna, tribuna y comentario son, según Grijelmo (1997: 137), los tres subgéneros del artículo de opinión. En el periódico costarriquense La Nación el español Fernando Díez Losano (1934-2015) publicó durante 22 años un artículo semanal, La Tribuna del idioma, v. Díez Losano (2004). Si no me equivoco, Martínez Albertos (52007) no utiliza el término tribuna en su tipología de los géneros periodísticos.

6. V., p. ej., la bibliografía de Quemada (1970-1972) sobre las chroniques de langage de Francia. Entre los trabajos pioneros hay que mencionar a Schwarze (1977), Hausmann (1981) y Christmann (1983). Desde entonces, los trabajos sobre este tipo de tradición textual se han multiplicado en el mundo francófono; v. para el francés canadiense la importante tesis doctoral de Remysen (2009) y otros trabajos suyos como, p.ej., Remysen (2010, 2011), etc. Para las language columns en el Reino Unido y en los EE UU, v. Pinker ([1994]/2011: 382-418), Cameron (1995: VII), Lampert (2009: 40).

7. V. también Lázaro Carreter (2003). Para una apreciación de la crítica lingüística de Lázaro Carreter, v. Lebsanft (1997: passim).

8. Es decir, hasta el último mes completo antes de mi ponencia en el coloquio ILPE 2 - Ideologías lingüísticas en la prensa escrita: el ejemplo de las lenguas románicas, Universidad de Sherbrooke, 29-31 de octubre de 2015. En los últimos tres meses de 2015 se publicaron 21 puntas más, en el año 2016 un total de otros 52 artículos que se pueden consultar en el sitio http://elpais.com/autor/alex_grijelmo/a/16 - http://elpais.com/autor/alex_grijelmo/a/18. 
aparecen reunidos artículos lingüísticos de Álex Grijelmo. Ya en 2004 había publicado La punta de la lengua. Críticas con humor sobre el idioma y el Diccionario, un libro que permite descubrir que la actual columna de El País reactiva otra con el mismo nombre, que el autor había tenido en la prensa española regional entre 2000 y 2002 (Grijelmo, 2004b: 11-15). Las fechas 2004 y 2012 marcan los momentos de su salida de la redacción del diario El País y de su reintegración. Durante el tiempo de su ausencia ocupó la presidencia de la agencia de noticias EFE en la que impulsó la creación de Fundéu BBVA, es decir, la Fundación de Español Urgente, fundación que continúa la conocida labor normativa del antiguo Departamento de Español urgente de EFE'. En el vídeo que se ha publicado en 2015 con motivo del acto de conmemoración del décimo aniversario de Fundéu se puede apreciar cuánto pesa el legado de Álex Grijelmo sobre las espaldas del actual presidente, cuando balbucea el nombre de su predecesor ${ }^{10}$.

\section{Análisis}

A continuación, pasamos al análisis cualitativo de nuestro corpus. Un primer examen superficial a partir de las opciones teóricas y de las técnicas analíticas empleadas por Grijelmo permite caracterizar los objetos lingüísticos que constituyen la materia de sus artículos. Comencemos entonces por las herramientas teóricas y analíticas utilizadas. Como hemos señalado ya, normalmente Grijelmo critica fenómenos lingüísticos que detecta en discursos concretos documentados, sobre todo de políticos, pero también de otros grupos profesionales, entre los que se hallan los periodistas. Al columnista no le parece apropiado, por ejemplo, el empleo de la colocación devolver la sonrisa con el sentido de "reparar la vida sentimental de una persona, formando pareja con ella". Para formular su crítica, se basa en un enunciado concreto, fechable:

El pasado 11 de noviembre, a las 14.50, proclamaban desde TVE refiriéndose a la exesposa de un político español recién divorciada: "Un atractivo mexicano de 47 años le ha devuelto la sonrisa”. Aquella mujer perdió la sonrisa con el divorcio (no durante el matrimonio, parece ser); y sólo una nueva relación se la devuelve. Y entre medias, nada: la tristeza. (Grijelmo, 1 de junio de 2013)

"Tal día, a tal hora, en tal medio" constituye el proceder empírico del columnista. En la tribuna de la que he sacado el ejemplo, el autor trae a colación no menos de tres enunciados contextualizados de esa manera. Dicho de manera más técnica y utilizando el esquema coseriano de la "estructura general del lenguaje" (Coseriu, 1981: 273) ${ }^{11}$

9. Para la labor lingüística de la Agencia EFE y su DEU, v. un análisis con mayor profundización en Lebsanft (1997: 185231).

10. V. http://www.fundeu.es/aniversario-fundeu/ [Sitio consultado el 6 de enero de 2017.], minuto 20:57.

11. Para una discusión de este modelo y de sus modificaciones ulteriores por Peter Koch y otros, v. Lebsanft (2015). 


\begin{tabular}{|c|c|c|c|}
\hline & \multicolumn{3}{|c|}{ punto de vista } \\
\hline niveles & $\begin{array}{l}\dot{\varepsilon} v \varepsilon ́ \rho \gamma \varepsilon 1 \alpha \\
\text { actividad }\end{array}$ & 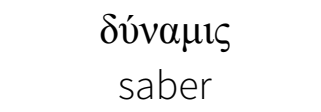 & 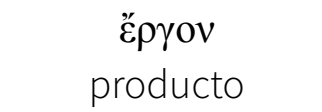 \\
\hline universal & hablar en general & saber elocucional & $\begin{array}{l}\text { totalidad de lo } \\
\text { "hablado" }\end{array}$ \\
\hline histórico & lengua concreta & saber idiomático & (lengua abstracta) \\
\hline individual & discurso & saber expresivo & "texto" \\
\hline
\end{tabular}

Coseriu: Estructura general del lenguaje

el análisis al que el columnista somete el enunciado se sitúa siempre en el nivel individual del discurso y del saber que le corresponde, es decir, del saber "expresivo". A partir de ahí surgen dos posibilidades. Por una parte, el crítico constata que la expresividad del locutor se mueve dentro de las posibilidades que la lengua y el discurso le ofrecen; por otra parte, descubre que la expresividad del locutor altera la estructura de la lengua y del saber "idiomático" correspondiente. Al respecto, a Grijelmo se lo puede tildar de "purista", si se entiende por el término la defensa de lo que la retórica antigua llamaba la puritas, es decir, la "corrección idiomática" en cuanto concordancia del discurso con el "sistema" de la lengua empleada"2.

Ahora bien, cuando yo hablo de "expresividad" en el sentido más técnico de "creación individual del discurso" y sin juicio valorativo ninguno, Grijelmo, por su parte, denuncia la "manipulación" del lenguaje y el cambio lingüístico negativo. Lo que importa aquí, desde el punto de vista teórico, es el hecho de que el columnista es plenamente consciente de la interacción entre los dos niveles estructurales del discurso y de la lengua. En vista de una divulgación de sus convicciones lingüísticas las expresa de forma más bien metafórica:

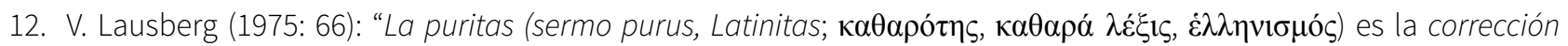
idiomática (es decir, en concordancia con el sistema del respectivo idioma) (recte loqui: $\S 92,1$ ) del discurso en los verba singula (§§ 108-124) y verba coniuncta (§§ 125-129)." La lingüística moderna prefiere centrarse en el aspecto negativo del purismo, incluyendo en el rechazo de lo ajeno no solo los idiomas extranjeros sino también la variación diasistemática de la propia lengua, v. la definición del purismo por Thomas (1991: 2) como "the manifestation of a desire on the part of the speech community (or some section of it) to preserve a language from, or rid it of, putative foreign elements held to be indesirable (including those originating in dialects, sociolects and styles of the same language)." En esta segunda línea de pensamiento hay que situar la dura crítica de Grijelmo por parte de Frühbeck Moreno (2017). 
[...] las palabras llegan siempre más allá de los límites con los cuales las petrifica el Diccionario. En sus páginas las vemos congeladas, y no por ello dejan de ser palabras con toda su esencia individual y su significado certero allí establecido. Pero en cuanto uno las saca de la nevera y las pone en el microondas, toman un olor y un calor que las transforma sin contradecirlas, igual que nos huele la sopa caliente sin dejar de ser sopa cuando está fría. Cada vocablo se muta al entrar en contacto con el contexto como el papel se altera al acercarse al fuego. (Grijelmo, 16 de junio de 2013)

Sin embargo, este lenguaje "poético" no debería ocultar una base teórica algo más sólida que la de la folk-linguistics tradicional ${ }^{13}$. Si esta base aflora en la columna periodística de manera solo muy fragmentaria - "el contexto suele afectar al significado de cada vocablo, como ha estudiado la pragmática (Austin, Grice y compañía)" (Grijelmo, 25 de abril de 2012) dice en algún momento -, una exposición nutrida y coherente de la teoría griceana del "sentido" en cuanto "significado contextualizado" la propone la obra La información del silencio, una monografía de más de 500 páginas (Grijelmo, 2012).

El Diccionario al que hace referencia - el diccionario académico, por supuesto - representa para Grijelmo la codificación del léxico a nivel de "lengua". De los 121 textos de nuestro corpus más de la mitad - 73 - conciernen a problemas de léxico, a saber, la introducción de nuevas palabras y locuciones o de nuevos sentidos. En ambos casos la atención se dirige hacia el contacto del español con el inglés, es decir, hacia los anglicismos integrales y los calcos semánticos. No obstante, el autor tematiza también la formación de palabras y la polisemia "autóctonas". El interés por la gramática es mucho menos intenso, con solo 12 textos centrados en esta temática. Mención aparte merece la alta frecuencia - se trata de 32 columnas - con la que Grijelmo aborda problemas de "estilo", es decir, la producción de sentido en enunciados completos.

Veamos, en una segunda aproximación a nuestro tema, un ejemplo típico de cómo procede el autor. Una de las primeras contribuciones de Grijelmo en el diario El País después del abandono de la presidencia de la Agencia EFE se titula "El rumor enmascarado" (Grijelmo, 29 de julio de 2012). Se trata de una crítica al condicional de conjetura en su modalidad de condicional de rumor periodístico que se emplea siempre que el locutor no quiere responder de la veracidad de los hechos relatados. Se utiliza, como dice la Nueva Gramática, para "presentar las informaciones de forma cautelosa o dar noticias no suficientemente contrastadas” (NGLE I, 2009: 1782 [§ 23.15m] ]14. La crítica de Grijelmo es doble. En primer lugar, pretende que el uso del condicional de rumor cause malentendidos; porque la lectura normal del condicional supone, según él, la presentación de un contenido no factual, hipotético:

13. Para ese concepto que traducimos por "lingüística popular" y "lingüística de los legos", v. Lebsanft (2017). Para la apreciación crítica de Grijelmo como ‘lego en lingüística’, v. también Longa (2015).

14. V. también, con bibiliografía, Rojo y Veiga (1999: 2916). 
Si leyésemos, por ejemplo, "Iniesta habría donado a los damnificados por los incendios de Valencia los 300.000 euros de la prima por la Eurocopa", podría pensarse que España no ganó el campeonato. Es decir, que Iniesta habría donado la prima si la hubiera conseguido. (Grijelmo, 29 de julio de 2012)

En segundo lugar, en el supuesto caso de la lectura correcta de condicional de conjetura, el rechazo de su empleo se basa en la norma deontológica de los periodistas según la cual los hechos no confirmados, es decir, los rumores "no son noticia” (El País, 2014: 32 [§ 1.24.]) 15. Sin embargo, el autor sabe cómo trasformar el relato de un rumor en noticia. Se trata de mencionar, simple y llanamente, la fuente no contrastada que se encuentra en el origen del hecho relatado. De esta manera, el periodista delega en su fuente la responsabilidad de la veracidad del enunciado:

[...] si la policía sospecha que el asesino es Fulano, escriba el periodista que la policía sospecha que el asesino es Fulano (lo cual no convierte a Fulano en asesino), en vez de barruntar que "el asesino habría sido Fulano", porque entonces pasamos de un hecho cierto (la policía sospecha) a uno inseguro (Fulano habría sido). (Grijelmo, 29 de julio de 2012)

A la hora de escribir esa columna, la discusión sobre el uso del condicional de rumor en el periodismo ya es un estereotipo en el sentido laboviano de la palabra, es decir, un elemento explícitamente evaluado dentro de la comunidad (Borrego Nieto, 1992: 122). Ahora bien, Álex Grijelmo lo sabe perfectamente y se inscribe voluntariamente en una tradición de rechazo del condicional de rumor, una tradición que presenta para él el dardo "Vivir en cantaría" del maestro Lázaro Carreter, publicado por primera vez hace 40 años (Lázaro Carreter, 1997: 95)ํ․ Pero hay más que eso. Grijelmo sabe perfectamente que la Nueva Gramática "parece tolerar ya” el uso que su predecesor censuraba. Por una parte, Grijelmo se somete a la autoridad de la Academia "desde el punto de vista gramatical"; por otra parte, la rechaza desde la perspectiva del estilo periodístico. "La propia Gramática precisa que los libros de estilo de algunos diarios prohíben este condicional" (Grijelmo, 29 de julio de 2012). Efectivamente leemos en la Nueva Gramática:

Algunos diarios hispanohablantes han optado por excluir este uso particular del condicional de conjetura en sus libros de estilo. No lo hacen, sin embargo, porque exista incorrección gramatical en dicha construcción, sino porque el rumor no debe ser presentado como noticia. (NGLE I, 2009: 1782 [§ 23.15m])

15. V. ya El País (1980: 17).

16. Informaciones, 22 de abril de 1976. 
Para Grijelmo, la oposición entre el nivel del discurso y el de la lengua, entre el saber expresivo y el saber idiomático, sirve para delimitar un terreno donde ni siquiera la Academia puede pisar ${ }^{17}$. Con referencia al léxico, donde la tolerancia cada vez mayor del Diccionario académico hacia los anglicismos merece su reprobación, afirma:

¿Pero valía la pena adoctrinar a los lectores para tanta batalla perdida? Seguramente responderán que sí, porque si les abandona el Diccionario les quedará siempre el refugio del estilo. El estilo es la elección: unos términos les parecen mejores que otros, aunque todos resulten correctos ya. (Grijelmo, 10 de abril de 2013)

Esa idea de aspirar a una ejemplaridad "pura", supuestamente más fina, más culta; es decir, más conocedora de las tradiciones lingüísticas del idioma que la de la propia Academia, es una constante en las puntas grijelmianas - una constante que comparte con el libro de estilo de su periódico ${ }^{18}$. Aduzcamos otro ejemplo aún más drástico. El columnista justifica el rechazo de la forma compleja gente anónima, admitida por el DLE (232014) bajo el lema anónimo ('indiferenciado, que no destaca de la generalidad'), con el argumento de que lo admitido a nivel de lengua se puede rechazar a nivel de discurso:

No obstante, muchas otras palabras han hallado su justo lugar en las páginas de la Academia y no por ello se justifica cualquier modo en que se empleen: eso depende del estilo y la ética de cada cual. Nadie discute que el término "mierda” perviva en el lexicón académico, pero eso no ampararía que se publicase en este periódico la frase "el debate de ayer fue una mierda”. (Grijelmo, 2 de marzo de 2014)

La Academia, por cierto, no ampararía el uso de ese enunciado en la prensa de calidad y, por eso, introduce la marca diafásica "voz malsonante" para indicar el nivel de uso de la palabra criticada (DLE, ${ }^{232014: ~ s . v .) . ~ P o r ~ o t r a ~ p a r t e, ~ n o ~ s e ~ v e ~ m u y ~ b i e n ~ c o ́ m o ~ s e ~ p o d r i ́ a n ~ m a r c a r ~ l o s ~ l i ́ m i t e s ~ d e ~ u s o ~ d e ~ l a ~}$ unidad pluriverbal gente anónima.

\section{Redes normativas}

El análisis de muy pocas columnas ha permitido esbozar cómo se perfila el discurso normativo de nuestro columnista frente a, por una parte, la tradición normativista divulgativa; y frente a la tratadística académica actual, por otra. Un tercer aspecto de nuestra temática concierne a la integración de las puntas de la lengua en la red de otras obras normativas actuales. Volviendo al uso del condicional de rumor periodístico, se puede comprobar que la codificación periodística actual se ocupa de

17. El condicional de conjetura es también usual en francés y en italiano, v. Lebsanft (2001: 293), Wilhelm (2006: 203-205). Según Wilhelm, se trata de un uso típicamente periodístico.

18. Sin embargo, ese normativismo se aplica allí de manera mucho más simplista, v. Lebsanft (2017). V. también la caracterización de Grijelmo por parte de Longa (2015: 88): "Más papista que el Papa”. 
igual manera de ese estereotipo normativo. El "manual" del Libro de estilo 2014 de El País lo rechaza también, en este caso por galicismo (ésta era la idea de Lázaro Carreter, no respaldada por la Nueva Gramática; El País, 2014: 177 [§ 13.28]). Ello no es motivo de sorpresa, puesto que Álex Grijelmo sigue siendo el máximo responsable del código lingüístico de su periódico. En una exposición más en detalle se podría demostrar que muchas entradas del "diccionario" del Libro de estilo actual retoman, de manera simplificada, las recomendaciones que Grijelmo elabora y expone en sus artículos. Cuando el Libro de estilo prescribe, s.v. "vuelta rápida":

En las competiciones de motor, casi todas lo son. Escríbase 'vuelta más rápida' o 'mejor vuelta', y no esa mala traducción de 'fastest lap'. (El País, 2014: 522)

el código lingüístico del periódico retoma no solo las conclusiones de la columna correspondiente, sino incluso hasta las palabras de su titular (“ 'Vuelta rápida’ lo son casi todas”, Grijelmo, 25 de agosto de 2013).

Otro asunto son las consultas y recomendaciones de la Fundación de Español Urgente. En el caso concreto del condicional, la Fundéu comparte el criterio de los periodistas de El País:

Como señala la Nueva gramática de la lengua española, de la Asociación de Academias de la Lengua Española, el condicional de rumor -que es el empleado para redactar noticias no suficientemente probadas o hacerlo de forma cautelosa- no es incorrecto desde el punto de vista gramatical, pero se desaconseja en algunos libros de estilo periodístico porque se utiliza para presentar suposiciones o meros rumores como noticias.

En la redacción de informaciones se recomienda sustituirlo por otras fórmulas que pongan de manifiesto el carácter conjetural de la información, como según fuentes consultadas, posiblemente, cabe la posibilidad de que, es posible que, se cree que...

Así, en ejemplos como "... Mainar se habría declarado único culpable del asesinato del alcalde de Fago", "Cuba habría negado la salida a un disidente" o "El Frente 48 de las FARC sería el responsable del ataque...", habría sido más adecuado utilizar fórmulas como "Según fuentes consultadas, Mainar se ha declarado único culpable...", "Cuba puede haber negado la salida a un disidente" o "Es posible que el Frente 48 de las FARC sea el responsable del ataque...". (Fundéu, 5 de febrero de 2007) ${ }^{19}$

Sin embargo, en otros muchos casos se desmarca de ellos. Demos un ejemplo de esas divergencias. A Grijelmo no le gustan ni el verbo externalizar ni el sustantivo deverbal externalización con los significados que corresponden al inglés to outsource y outsourcing (Grijelmo, 9 de febrero de 2014). No obstante, su crítica no se focaliza en el préstamo lingüístico, sino en la formación de estas palabras y en la intención supuestamente eufemística que es, según él, la causa profunda de estos neologismos.

19. El criterio de Fundéu BBVA (2015: 101) es menos rígido: "Conviene no abusar del llamado condicional de rumor [...]. Este condicional [...] podría sustituirse por otras construcciones [...]. Sin embargo, no es gramaticalmente incorrecto y en ocasiones permite ahorrar espacio en los titulares." 
Efectivamente, el columnista construye una conexión entre la forma alargada, "sesquipedálica"20 y la finalidad eufemística:

Podemos contestar que no usábamos antes "externalización" porque tal cosa se llamaba "contrata" o "subcontrata", que son las ideas sustituidas por este palabro. Las críticas que se asociaron a esos términos, y quizás la mayor proporción de accidentes laborales en las subcontratas de la construcción, incitaron a inventar otro vocablo que prestigiara tal ardid cuando concerniese a los servicios públicos. Y para ese menester las palabras largas siempre se han considerado un valor seguro. (Grijelmo, 9 de febrero de 2014)

La recomendación de la Fundéu, formulada con anterioridad (8 de mayo de 2013), defiende la palabra externalización como equivalente adecuado del término inglés outsourcing. A diferencia de Grijelmo, la Fundéu distingue entre externalización y subcontratación, que es el caso especial de la "externalización de la actividad propia" (Fundéu, 8 de mayo de 2013)21. La posición de la Fundéu cuenta con el respaldo de la Real Academia que incluye las palabras externalizar y externalización en la nueva edición de su Diccionario (DLE, ${ }^{23} 2014$ : s.v.).

Curiosamente, el antiguo promotor de la Fundéu, que es Álex Grijelmo, elude, en esta y en otras muchas ocasiones, cualquier diálogo con sus hermanos en el espíritu normativo, cuyas recomendaciones preceden tantas veces las columnas correspondientes de El País. Por supuesto, no queremos restar ni originalidad ni méritos a las puntas de la lengua que defienden posiciones normativas propias frente al consenso que existe normalmente entre la Fundéu y la Academia. Además, hay, en los artículos de Grijelmo, una temática específica que no tiene parangón en los discursos normativos vecinos. Se trata de la vinculación de la ejemplaridad lingüística con la ejemplaridad ética. Efectivamente, la publicación de La información del silencio. Cómo se miente contando hechos verdaderos (Grijelmo, 2012) sirve de base para un discurso normativo cada vez más moralizante. Esta ética de la conducta lingüística, basada en la teoría griceana de la comunicación, ${ }^{22}$ se entrevé en los pocos ejemplos que hemos podido aducir y aún es mucho más manifiesto en otros artículos cuyo análisis reservamos para otras ocasiones. Cuanto más ético pretende ser el discurso normativo tanto menos rígidos deberían ser los juicios que se emiten. Esta parece ser la divisa de Grijelmo:

Lo importante cuando se habla del idioma no es tener razón, sino tener debate: reflexionar, preguntarse. Cuanta más gimnasia hagamos sobre el lenguaje, más difícil será que nos manipulen con él (Grijelmo, 12 de abril de 2015).

20. La crítica a las palabras alargadas es una constante en Grijelmo, v. Grijelmo (1997: 441-443), Grijelmo (2000: 147s.). Con esta crítica se inscribe en una tradición que remonta, al menos, al columnista de ABC, Luis Calvo (1898-1991), v., entre muchos otros ejemplos, Calvo (23 de junio 1984): "sesquipedálico, que define a las palabras excesivamente largas, como, por ejemplo, estatuarización”. V. también De Miguel, “polisilabismo” (1985: 119-122).

21. V. también la misma diferenciación en Fundéu BBVA (2015: 174) S.v. "externalización".

22. Sobre las bases éticas de la teoría de Grice v. el apartado “Ethics” en Grandy/Warner (2017). 
Parece ser una divisa prometedora para concluir. Sin embargo, no lo hacemos porque existe también esa otra cara del columnista, que sí quiere tener razón y que es consciente de ello con una confesión que caracteriza al homo normativus. La expresión lingüística que corresponde a la mímica de esta cara reza así:

Todo hablante del castellano alberga seguramente en su interior un pequeño purista. Quien más, quien menos, cree incorrecto algo, o le suena mal, por muy abierto que se sienta a la innovación. Los cambios que se habían producido cuando nacimos no nos resultan extraños, pero sí los que se desarrollan ante nosotros. (Grijelmo, 30 de agosto de 2015)

No obstante, el hecho de que los lingüistas descriptivos combatan con muy buenos argumentos científicos ${ }^{23}$ ese "pequeño purista", no impide que siga existiendo y que se corresponda, quizá, con una realidad intrínseca de la condición lingüística humana. ${ }^{24}$

23. Para la discusión sobre el purismo en la España de finales del siglo XX, v. Lebsanft (1997: 28-31, 59-63), Lebsanft (2017); v. también las contribuciones polémicas de Longa (2015) y Frühbeck Moreno (2017).

24. V. Bloomfield (1927: 43): "The nearest approach to an explanation of 'good' and 'bad' language seems to be this, then, that by a cumulation of obvious superiorities, both of character and standing, as well as of language, some persons are felt to be better models of conduct and speech than others. Therefore, even in matters where the preference is not obvious, the forms which these same persons use are felt to have the better flavor. This may be a generally human state of affairs, true in every group and applicable to all languages". Con estas palabras, Bloomfield se refiere al idioma de los menomini; describe el buen uso de ese idioma en términos que reflejan claramente una ideología purista existente tanto en la comunidad lingüística indígena como en el lingüista objetivo que Bloomfield pretende ser. V. también la "confesión" purista del lingüista antipurista Pinker ([1994]/2011: 416), que cito arriba. Pinker opta por posturas claramente puristas, cf. su nueva defensa de la diferencia semántica entre uninterested y disinterested: "[...] since we have the word uninterested and lack an exact synonym for disinterested, readers will appreciate your maintaining the distinction" (Pinker 2015: s.p.). 


\section{Bibliografía}

Fuentes digitales [Sitios consultados el 6 de enero de 2017.]

Calvo, Luis ("El Brocense", 23 de junio de 1984), "Anglicismos e ignorancia", disponible en http://hemeroteca.abc.es/nav/Navigate.exe/hemeroteca/madrid/abc/1984/06/23/054.html.

Fundéu (5 de febrero de 2007), "Condicional de rumor", disponible en http://www.fundeu.es/recomendacion/condicional-de-rumor-179/.

Fundéu (8 de mayo de 2013), "externalización, palabra adecuada en español", disponible en http://www.fundeu.es/recomendacion/externalizacion-palabra-adecuada-en-espanol/.

Grijelmo, Álex (25 de abril de 2012), "Cambiar las palabras o cambiar la realidad”, disponible en http://elpais.com/elpais/2012/04/13/opinion/1334317018_255863.html.

Grijelmo, Álex (29 de julio de 2012), "El rumor enmascarado", disponible en http://elpais.com/elpais/2012/07/19/opinion/1342716341_843818.html.

Grijelmo, Álex (10 de abril de 2013), “El dardo en lo ostentóreo”, disponible en http://cultura.elpais.com/cultura/2013/04/10/actualidad/1365591930_838486.html.

Grijelmo, Álex ( $1^{\circ}$ de junio de 2013), "Palabras con prejuicios", disponible en http://elpais.com/elpais/2013/05/22/opinion/1369249096_684774.html.

Grijelmo, Álex (16 de junio de 2013), "Ejecutar un asesinato", disponible en http://elpais.com/elpais/2013/06/13/opinion/1371134621_393107.html.

Grijelmo, Álex (25 de agosto de 2013), "”vuelta rápida” lo son casi todas”, disponible en http://elpais.com/elpais/2013/08/22/opinion/1377196760_915951.html.

Grijelmo, Álex (9 de febrero de 2014), “Lo contrario de “externalización” es 'casting”, disponible en http://elpais.com/elpais/2014/02/07/opinion/1391777204_502277.html.

Grijelmo, Álex (2 de marzo de 2014), "La gente anónima tiene nombre”, disponible en http://elpais.com/elpais/2014/02/28/opinion/1393614247_430176.html.

Grijelmo, Álex (13 de julio de 2014), "Abdicar la corona con corrección”, disponible en http://elpais.com/elpais/2014/07/11/opinion/1405073389_894607.html.

Grijelmo, Álex (12 de abril de 2015), “Cosas que 'le' importan a veinticinco", disponible en http://elpais.com/elpais/2015/04/10/opinion/1428680234_892269.html.

Grijelmo, Álex (30 de agosto de 2015), "La tilde sentimental", disponible en http://elpais.com/elpais/2015/07/24/opinion/1437737781_691265.html.

Grijelmo, Álex (10 de enero de 2017), "Dress code' sale de fiesta”, disponible en http://elpais.com/elpais/2016/12/23/opinion/1482489956_634989.html. 


\section{Fuentes impresas}

De Miguel, Amando ([1985]/1994), La perversión del lenguaje, Madrid, Espasa Calpe.

Díez Losano, Fernando (2004), La tribuna del idioma, Cartago/Costa Rica, Ed. Tecnológica de Costa Rica.

El País (1980), Libro de estilo, Madrid, PRISA.

El País (2014), Libro de estilo, México, D.F., Aguilar.

Fundéu BBVA (2015), Manual de español urgente. Segunda época, Barcelona, Penguin Random House.

Grijelmo, Álex (1998), Defensa apasionada del idioma español, Madrid, Taurus.

Grijelmo, Álex (2000), La seducción de las palabras, Madrid, Taurus.

Grijelmo, Álex (2004a), El genio del idioma, Madrid, Taurus.

Grijelmo, Álex (2004b), La punta de la lengua. Críticas con humor sobre el idioma y el Diccionario, Madrid, Aguilar.

Grijelmo, Álex (2006), La gramática descomplicada, Madrid, Taurus.

Grijelmo, Álex (2012), La información del silencio. Cómo se miente contando hechos verdaderos, Madrid, Taurus.

Grijelmo, Álex (2015), Palabras de doble filo. Avisos y antídotos contra engaños y calamidas, Madrid, Espasa.

Lázaro Carreter, Fernando (1997), El dardo en la palabra, Barcelona, Galaxia Gutenberg.

Lázaro Carreter, Fernando (2003), El nuevo dardo en la palabra, Madrid, Aguilar.

Pascual, José Antonio (2013), No es lo mismo ostentoso que ostentóreo. La azarosa vida de las palabras, Barcelona, Espasa. 


\section{Literatura}

Bloomfield, Leonard (1927), "Literate and Illiterate Speech", American Speech, vol. 10, p. 432-439.

Borrego Nieto, Julio (1992), “Actitudes y prejuicios lingüísticos: la norma interna del hablante”, en José Antonio Bartol Hernández, Javier de Santiago Guervós y Juan Felipe García Santos (eds.), Estudios filológicos en homenaje a Eugenio de Bustos Tovar, 2 vols., Salamanca, Universidad, vol. 1, 121-136.

Cameron, Deborah (1995), Verbal Hygiene, London, Routledge.

Christmann, Hans Helmut (1983), "Das Französische der Gegenwart. Zu seiner Norm und seiner défense", en Franz Josef Hausmann (ed.), Die Französische Sprache von heute, Darmstadt, Wissenschaftliche Buchgesellschaft, p. 411-440.

Coseriu, Eugenio (1981), Lecciones de lingüística general, Madrid, Gredos.

DLE (232014) = Real Academia Española, Diccionario de la lengua española, Barcelona, Espasa.

$D E A=$ Seco, Manuel, Olimpia Andrés y Gabino Ramos, Diccionario del español actual, 2 vols., Madrid, Santillana.

Frühbeck Moreno, Carlos (2017), "En busca del genio del idioma: La labor purista de Álex Grijelmo", Tonos Digital, vol. 32, disponible en http://www.tonosdigital.com/ojs/index.php/tonos/article/view/1622/881. [Sitio consultado el 6 de enero de 2017.]

Grandy, Richard E. y Richard Warner, "Paul Grice" (2017), The Stanford Encyclopedia of Philosophy, https://plato.stanford.edu/archives/win2017/entries/grice/. [Sitio consultado el 25 de octubre de 2017.]

Grijelmo, Álex (1997), El estilo del periodista, Madrid, Taurus.

Hausmann, Franz Josef (1981), "Le français régional vu à travers une chronique de langage: 'Parlons français' dans La Voix du Nord", en Dieter Kremer y Hans Josef Niederehe (eds.), Littératures et langues dialectales françaises. Actes du Colloque de Trèves du 17 au 19 mai 1979, Hamburg, Buske, p. 107-116.

Lampert, Günther (1998), "To Hell with the Future, we'll Living in the Past: Ideas and Ideologies of Language Culture in Britain”, en Albrecht Greule y Franz Lebsanft (eds.), Europäische Sprachkultur und Sprachpflege, Tübingen, Narr, p. 37-62.

Lausberg, Heinrich (1975), Elementos de retórica literaria, Madrid, Gredos.

Lebsanft, Franz (1997), Spanische Sprachkultur. Studien zur Bewertung und Pflege des öffentlichen Sprachgebrauchs im heutigen Spanien, Tübingen, Niemeyer.

Lebsanft, Franz (2001), "Sprache und Massenkommunikation”, en Günter Holtus, Michael Metzeltin y Christian Schmitt (eds.), Lexikon der Romanistischen Linguistik, vol. 1/2, Tübingen, Niemeyer, p. 292-304. 
Lebsanft, Franz (2015), "Aktualität, Individualität und Geschichte. Zur Diskussion um den theoretischen Status von Diskurstraditionen und Diskursgemeinschaften", en Franz Lebsanft y Angela Schrott (eds.), Diskurse, Texte, Traditionen. Modelle und Fachkulturen in der Diskussion, Göttingen, $\checkmark \& R$ Unipress, p. 97-113.

Lebsanft, Franz (2017), "Lingüística popular y codificación del español", en Wolfgang Dahmen et al. (eds.), Sprachberatung und Sprachkritik in der Romania. Romanistisches Kolloquium XXX, Tübingen, Narr, p. 103-118.

Longa, Víctor M. (2015), "iLa lengua se corrompe! Prescriptivismo y representaciones apocalípticas sobre el lenguaje en un 'jeremías' actual”, Representaciones, vol. 11, p. 81-116, disponible en https://revistas.unc.edu.ar/index.php/repr/article/view/13325/13521 . [Sitio consultado el 6 de enero de 2017.]

Martínez Albertos, José Luis (52007), Curso general de redacción periodística, Madrid, Thomson.

NGLE = Real Academia Española y Asociación de Academias de la Lengua Española (2009-2011), Nueva gramática de la lengua española, 3 vols., Madrid, Espasa.

Pinker, Steven ([1994]/2011), The Language Instinct. How the Mind Creates Language, New York, Harper Perennial.

Pinker, Steven (2015): The Sense of Style. The Thinking Person's Guide to Writing in the 21 ${ }^{\text {st }}$ Century, New York, Viking.

Quemada, Bernard (ed.) (1970-1972), Bibliographie des chroniques de langage publiées dans la presse française, vol. 1, 1950-1965, vol. 2, 1966-1970, Paris, Didier.

Remysen, Wim (2009), Description et évaluation de l'usage canadien dans les chroniques de langage. Contribution à l'étude de l'imaginaire linguistique des chroniqueurs canadiens-français, Québec, Université Laval.

Remysen, Wim (2010), "Le discours normatif des chroniqueurs de langage canadiens-français : arguments avancés pour justifier certains emplois qui ont cours en français du Canada”, en Maria Iliescu, Heidi M. Siller-Runggaldier y Paul Danler (eds.), Actes du XXVe Congrès international de linguistique et de philologie romanes (Innsbruck, 3-8 septembre 2007), vol. 1, Berlin, de Gruyter, p. 673-684.

Remysen, Wim (2011), "L'application du modèle de l'imaginaire linguistique à des corpus écrits. Le cas des chroniques de langage dans la presse québécoise", Langage et société, n 135, p. 47-65.

Rojo, Guillermo y Alexandre Veiga (1999), "El tiempo verbal, los tiempos simples”, en Ignacio Bosque y Violeta Demonte (eds.), Gramática descripitiva de la lengua española, vol. 2, Madrid, Espasa Calpe, p. 2867-2934.

Schwarze, Christoph (1977), Sprachschwierigkeiten, Sprachpflege, Sprachbewußtsein. Das Phänomen der "Chroniques de langage", Konstanz, Universitätsverlag.

Thomas, George (1991), Linguistic Purism, London, Longman. 
Wilhelm, Raymund (2006), "Einzelsprachliche Syntax und journalistische Diskurstradition. Zur Tempusverwendung in der Gazzetta di Milano (1769/1786)", en Wolfgang Dahmen et al. (eds.), Historische Pressesprache. Romanistisches Kolloquium XIX, Tübingen, Narr, p. 197-225. 